\title{
Author Spotlight: Federica Gagliardi
}

\section{Federica Gagliardi ${ }^{1}$}

Accepted: 17 November 2021 / Published online: 30 January 2022

(c) The Author(s), under exclusive licence to Springer Science+Business Media, LLC, part of Springer Nature 2021

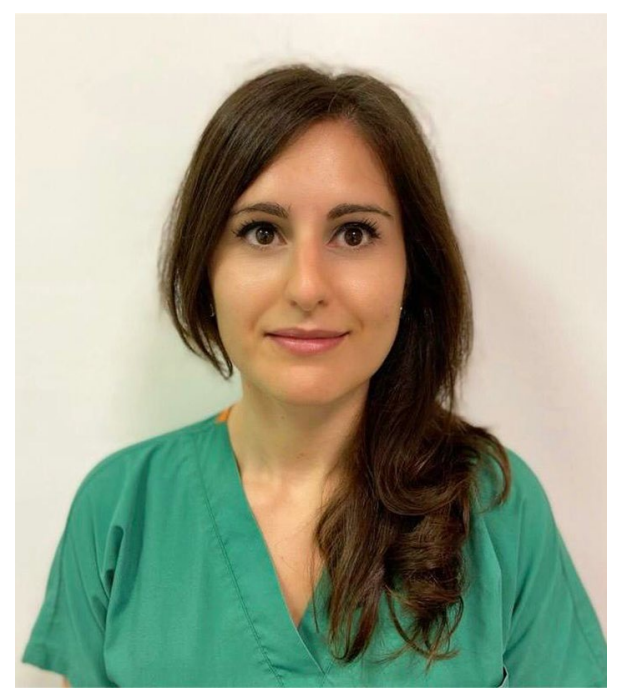

Federica Gagliardi, MD (federica.gagliardi@uniroma1.it), is a fourth-year general surgery resident at the Department of Surgical Sciences, Sapienza University of Rome. She completed her MD at Sapienza University of Rome continuing as a resident, where she is now learning all aspects of general and breast surgery. She has an interest in colorectal diseases, focusing on laparoscopic surgery of colorectal malignancy.
Publisher's Note Springer Nature remains neutral with regard to jurisdictional claims in published maps and institutional affiliations.

Federica Gagliardi

federica.gagliardi@uniroma1.it

1 Department of Surgical Sciences Sapienza, University

of Rome, Rome, Italy 